\title{
A TOPOLOGIA IMAGINÁRIA NAS OBRAS DE ARTEMÍDIA: HABITAR ESPAÇOS RIZOMÁTICOS
}

\author{
Gabriela Freitas ${ }^{1}$
}

\section{Resumo}

A partir de um diálogo entre as noções de rizoma, em Deleuze e Guattari, habitar (ser-em) em Heidegger e de devaneio, em Bachelard, propomos, neste artigo, compreender como as instalações de artemídia constituem um espaço híbrido entre imagens visíveis e imagens mentais, entre luz e sombra e entre real e virtual. Tal hibridismo constitui uma experiência única e subjetiva, pois dialoga com as vivências e memórias individuais de cada participador que percorre tais instalações e, dessa forma, completa seu sentido. A topologia imaginária que aí se forma envolve uma interação que parte da percepção aos diferentes estados de consciência por meio do resgate de imagens reminiscentes em processos de lembrança, como defende Merleau-Ponty.

Palavras-chave: Topologia Imaginária, Artemídia, Habitar, Rizoma, Devaneio

\begin{abstract}
On the basis of a dialogue among the rhizome concepts in Deleuze and Guattari, to Dwell (be-in) in Heidegger and reverie in Bachelard, we propose in this paper to understand how media art instalations are a hybrid space between visible images and mental images, between light and shadow, and between real and virtual. This hybridity is a unique and subjective experience, it dialogues with individual experiences and memories of each participant who runs across such instalations and thus complete its meaning. The imaginary topology that is formed there involves an interaction that starts from the perception of the different states of consciousness through the redemption of reminiscent images in memory processes, as advocated by Merleau-Ponty.
\end{abstract}

Keywords: Imaginary topology, Media Art, Dwelling, Rhizome, Reverie

\footnotetext{
${ }^{1}$ É professora adjunta da Universidade de Brasília, com participação no grupo de pesquisa ComVersações do programa de pós-graduação da Faculdade de Comunicação (UnB), linha de Imagem, Som e Escrita. ossui doutorado em Comunicação pela Universidade de Brasília (2014) com período de doutoramento sanduíche na Université Sorbonne (Paris - IV), em Paris. Mestrado em Comunicação pela Universidade de Brasília (2009). Mestrado profissionalizante em Visual Design pela Scuola Politècnica di Design de Milão (2005). Graduação em Publicidade (UnB /2002) e Especialização em Graphic Advertising pelo Istituto Europeo di Design de Milão (2000).
} 
Quando observamos obras contemporâneas de artemídia contemporânea podemos destacar a importância do percurso do participante pela obra, construindo sua própria interpretação e diálogo com o trabalho exposto, ao escolher seu trajeto pelas instalações que chamam o corpo à experiência sensorial. Justamente pela proposta dialógica dessas obras, elas se constituem a partir de um híbrido de linguagens e categorias artísticas, chegando a provocar uma zona de indiscernibilidade entre o lugar do museu e a vida cotidiana (GOLDBERG;2014:23). Vemos que a dimensão do espaço, neste caso, ganha importância como local de experiência, de possibilidade de realização de dobras subjetivas no tempo. Nesse cenário, objetos artísticos se misturam a objetos não artísticos, propondo uma topologia $^{2}$ fragmentada que se completa apenas mediante a presença ativa, não apenas corpórea, mas também mental e imaginária do participador.

A noção de topologia carrega em si a sensação de movimento. Compreender como se dá esse movimento é desvendar os trajetos e percursos da topologia das obras de artemídia. Devemos entender que a geografia da qual tratamos aqui é uma geografia rizomática do movimento — daí, mais uma vez, a impossibilidade de nos voltarmos à cartografia. Esse rizoma, no entanto, só se completa mediante o trajeto percorrido pelo participador. Dessa forma, a topologia da obra é fluida, pois se configura somente no trânsito que se torna possível pelas passagens deixadas em aberto no diálogo entre linguagens dessas instalações multimídia que, em sua maioria, são híbridas.

A ideia de rizoma, segundo Deleuze e Guattari (1995), implica justamente uma multiplicidade da qual é possível partir linhas de fuga, ou seja da qual é possível subtrair o único. Cada vivência de obra resulta numa percepção e interpretação diferente. Mais do que obra aberta, como propunha Umberto Eco, a obra de artemídia é viva, se completa a partir do movimento e da relação, em constante fluxo. Dois dos princípios do rizoma, inclusive,

\footnotetext{
${ }^{2}$ A noção de topologia liga-se à ideia de relevo que, por sua vez, contempla o movimento: altos, baixos e pontos de destaque - o que pode se relacionar à forma como cada um percorre as experiências propostas pela artemídia a partir do diálogo com suas imagens mentais, por exemplo. Ainda sobre o conceito de topologia, a área da teoria da informação enxerga aí uma rede em suas mais variadas formas, enquanto que para um ramo da geometria matemática, a topologia se baseia na noção de um espaço não-quantitativo em que apenas se consideram as relações de posição entre elementos das figuras - tal como num rizoma, que não se define pelos pontos, mas, pela passagem entre eles, constituindo-se pelo meio ou pela relação. Além disso, em sua própria etimologia, temos a relação com os termos "topo" (lugar) e "logos"(conhecimento). Para Heráclito, o conceito de logos é bastante caro, pois tem sua significação para além do entendimento comum que a liga apenas à racionalidade. Para o efésio, logos estaria ligado a uma esfera única que abrange tanto o ser quanto o ente do homem - formando uma coletividade originária, como aponta Heidegger em seus estudos sobre o filósofo.
} 
segundo os dois autores, são o de conexão e de heterogeneidade, ou seja, qualquer ponto de um rizoma pode e deve ser conectado a qualquer outro e não cessaria de conectar cadeias de significação, reforçando sua natureza transitória e instável. Esses dois princípios dialogam também com o da ruptura, que reforça o fato do rizoma poder se interromper a qualquer momento, em qualquer ponto e, ainda assim, promover, por meio de outras multiplicidades, a criação de novas significações.

Deleuze e Guattari afirmam que essa multiplicidade rizomática, no entanto, se constitui num plano, uma vez que ocupam todas as suas dimensões. Nesse ponto compreendemos o porquê dos autores se referirem a uma cartografia e percebemos que não discordamos por completo do pensamento por eles elaborado. Apenas propomos dialogar esse pensamento com a percepção visual, sensorial e as vivências pessoais que se formam a partir dele. Ao pensar em uma multiplicidade que promove a relação entre exterior e interior, em todas as dimensões, imaginamos um rizoma tridimensional que se expande no espaço e que adentra corpos, imagens e objetos, com movimento e relevo. Mais uma vez, pensar numa planificação do rizoma nos remete à ideia de permanecer na esfera da separação entre sujeito e objeto, como se aí não houvesse diálogo. As linhas que ligam os diversos pontos, e que se transformam constantemente, formam um espaço onde o participador também se insere principalmente quando falamos das instalações de artemídia. Em tal espaço, não prevalece a representação tradicional, mas sim a atitude criativa, que emprega a imagem em relações de aproximação e vizinhança com o real, já que considera também as imagens mentais provenientes da participação subjetiva.

Tal imagem, para Warburg, projeta um duplo visível de seu referente, constituindo uma constelação que vai em direção à dimensão energética (apud SIEREK:2009:172), transitando do atual ao virtual, chegando mesmo a se desprender do espaço físico e referencial (Ibidem:164). Dessa forma, podemos conceber uma imagem sem espaço, porém idealizada a partir da relação com outras imagens numa experiência que, de início, se deu a partir de outra imagem (essa, sim, inserida num determinado espaço). Dá-se, aí, uma ruptura no rizoma que sustenta essas ligações, porém essa não é uma ruptura definitiva, mas, sim, uma reconfiguração da rede que sustenta essa constelação e, ao implodir a topologia visível cria, segundo uma visão fenomenológica, uma topologia imaginária, fruto da experiência subjetiva originada no visível. É um rizoma não apenas multidimensional, mas transdimensional, que se forma na interação entre experiências diversas tal como na engrenagem que movimenta o mundo fenomenológico, segundo Merleau-Ponty (2011:18). 
Na obra Descendo a Escada $(2002)^{3}$, de Regina Silveira ${ }^{4}$, podemos observar um exemplo dessa topologia transdimensional e híbrida, constituída entre o referente visível e as imagens mentais individuais que completam a experiência. $\mathrm{O}$ ambiente que acolhe a obra é totalmente escuro e um projetor cria uma escada virtual, em movimento, simulando a descida de quatro andares. A escala e a perspectiva da imagem em movimento são pensadas de modo que o observador-participador da obra possa seguir o movimento, como se ele estivesse realmente descendo uma escada materialmente visível. Para aumentar a sensação de realismo, ouve-se o som de passos de outros supostos participantes que poderiam estar em outros andares. A projeção nos leva a descer até uma sala escura e, ao chegar aí, a imagem retorna ao estado inicial, num movimento de trás para frente, rápido e vertiginoso.

A imagem luminosa é pobre de detalhes. São feixes de luz que mais se assemelham a uma estrutura inacabada, ou a um desenho apenas feito de linhas. Ao estimular uma sensação de imersão, mediante o movimento, a perspectiva e o som, o participante acaba por completar a sua experiência com a obra e, consequentemente, da imagem, relacionando-a às imagens mentais de escadas que estão guardadas em sua memória. Que sejam as escadas da casa da infância (como talvez o fizesse Bachelard!), ou escadas nunca percorridas, mas já vivenciadas pela imaginação através das pinturas de Escher $^{5}$, por exemplo.

A experiência proposta por Regina Silveira nos leva a esse estado de entre-mundos que se forma na oscilação entre luz e sombra, entre real e virtual, buscando seus referenciais entre imagens projetadas e mentais. O que resulta daí é uma imagem mista e nebulosa que irá formar, para o participante, mais um parâmetro visual de "escada", a partir de uma relação entre imagens, matérias e sensações. Uma experiência que se manifesta numa topologia imaginária que, por meio da oscilação, constrói a percepção híbrida e complexa da obra.

Segundo Bachelard, o espaço percebido pela imaginação não pode ser o espaço entregue à mensuração por um geômetra, mas, sim, um espaço vivido com todas as parcialidades da imaginação. É um espaço que atrai: "No reino das imagens, o jogo entre o exterior e a intimidade não é um jogo equilibrado. [...] Incessantemente, a imaginação imagina e se enriquece com novas imagens.”(2008:19). Nessa dinâmica, o espaço retém o tempo, que se desenrola no ritmo da experiência e não mais de forma linear: "nosso espaço

\footnotetext{
${ }^{3}$ Disponível em <https://www.youtube.com/watch?v=Sbm6YJ_F9Xg>. Acessado em 25/03/2016.

${ }^{4}$ Regina Silveira (1939 - ) é artista e professora aposentada da USP. Site da artista: < www.reginasilveira.com $>$

${ }^{5}$ Artista gráfico holandês $(1898$ - 1972). Para conhecer mais sobre o artista: < http://www.mcescher.com/ >
} 
tornou-se temporal ou nosso tempo se espacializou, perguntam-se vários pensadores." (VENTURELLI; 2011:23).

Para Edmond Couchot, a relação espaço-tempo, quando aparelhada por uma rede numérica, leva o sujeito a adquirir uma espécie de ubiquidade dialógica alimentada por uma percepção rizomática fruto da relação mesma entre homem e máquina (1998:230). Uma questão levantada pelo autor é que, nesse cenário, nos encontramos num estado a meio caminho entre o individual e o coletivo, indo ao encontro à filosofia de Deleuze acerca do espaço, em que se concebe uma dissolução da separação entre o interior e o exterior: "o espaço-tempo deixa de ser um dado puro para se tornar o conjunto ou o nexo das relações diferenciais no sujeito, e o próprio objeto deixa de ser um dado empírico para se tornar produto dessas relações na percepção consciente.”(1991:134). Para o filósofo, isso se manifesta na imanência da percepção e do pensamento, ou, como preferimos abordar, na trans-imanência.

A noção espacial dessas instalações não é apenas fruto das redes multimídia, digitais ou tecnológicas, mas de redes que se comunicam e se formam entre visibilidades, materialidades, percursos e, principalmente, experiências diversas. Acontece que as facilidades de se explorar o hibridismo de linguagens, proporcionado pelas plataformas multimídia e digitais, nos levam a observar e questionar a multiplicidade que se manifesta nesses tipos de obra. Para Arlindo Machado, vivenciamos o que se convencionou chamar de segundo barroco, ou neobarroco, caracterizado pela instabilidade: "Do espaço isotópico da figuração clássica, [...] passamos agora ao espaço politópico, em que elementos constitutivos do quadro migram de diferentes contextos espaciais e temporais e se encaixam [...] em configurações híbridas” (2010:76).

Podemos dizer que pensar numa topologia imaginária consiste em pensar também numa geografia rizomática do movimento que é híbrida entre visível e imaginário, entre real e virtual, entre percepção e experiência, pois se baseia na experiência estética (aisthesis). As imagens que constituem essa rede topológica são, como propõe Sierek, imagens-pássaro (images oiseaux): “Leves e volúveis, elas estão em constante movimento.” (2009:197) para, assim, permitir o trânsito entre interior e exterior, sujeito e objeto - transcendência imanente.

Criar uma topologia imaginária consiste em estabelecer um diálogo entre imagens visíveis e mentais. A experiência que aí se constrói parte de uma percepção que não deixa de retomar as experiências de percepções anteriormente vividas. Para Merleau-Ponty, a 
significação daquilo que é percebido forma uma constelação de imagens que reaparecem sem razão (2011:38) num diálogo entre exterior e interior. Bachelard também se questiona sobre como o aparecimento de uma imagem efêmera e singular pode reagir em diversas almas, criando, muitas vezes, uma espécie de transubjetividade que ultrapassa o senso comum. Para o filósofo, apenas a fenomenologia, ao considerar o início da imagem numa consciência individual, pode ajudar a compreender essa subjetividade que caracterizamos como rizomática.

O fenomenólogo, segundo Bachelard, parte de observações simples para chegar à experiência, compreendendo que a imagem vem antes do pensamento e forma uma consciência sonhadora (2008:3-4). Com a contribuição do autor podemos compreender melhor, então, a afirmação de Merleau-Ponty em relação à composição da percepção — sobre a qual apenas demos um vislumbre logo acima. Ele afirma que apenas a "projeção das recordações" não é o suficiente para se introduzir na percepção atual uma atividade mental. A construção perceptiva é também uma atividade empírica que se baseia nos estados de consciência: parte de estímulos externos e percepções visíveis para dialogar no campo do invisível, gerando tal constelação de imagens que funda a experiência. Dessa forma, não há como negar que cada sujeito perceba a mesma imagem, cor ou nota musical a partir de um estímulo externo. O que muda, segundo Deleuze, é a atualização dessa percepção em cada um, reforçando a noção de que a experiência se estrutura numa percepção elaborada sobre múltiplos estados de consciência (dentre as quais, também a consciência sonhadora de Bachelard).

Dessa forma, a percepção ganha uma dimensão dupla que se constitui na relação entre o externo e o interno e assume, segundo Deleuze, uma característica alucinatória. Para o filósofo a percepção não tem um objeto, mas remete a um mecanismo psíquico das relações entre as pequenas percepções, constituindo um mundo próprio (1991:141). A primeira etapa da percepção, portanto, iria do sujeito ao objeto, pois as pequenas percepções evocam a vibração na matéria do objeto, levando a uma percepção consciente pelo órgão receptor nesse mesmo sujeito e fazendo ambos (sujeito e objeto) coincidirem. A percepção, dessa maneira, pode ser compreendida como uma representação do objeto e do mundo (repercutindo o ser-aí heideggeriano) pois, segundo Deleuze, as dobras internas que constituem o sujeito se assemelham à matéria que também constitui as dobras externas (1991:147-148).

Neste ponto, podemos retomar o pensamento de Merleau-Ponty que diz que "perceber não é experimentar um sem-número de impressões que trariam consigo recordações capazes 
de completá-las, é ver jorrar de uma constelação de dados um sentido imanente sem o qual nenhum apelo às recordações seria possível." (2011:47). De forma que, quando nos recordamos, as experiências que resgatamos são vividas novamente, em outra situação espaço-temporal: vivências internas que se tornam possíveis por empréstimo do estímulo de uma experiência externa, àquela proposta no momento. A percepção, portanto, pode ser considerada um conhecimento originário, pois aquilo que agora parece indeterminado para mim, tornar-se-á determinado para um conhecimento mais completo que está antecipadamente realizado no objeto (MERLEAU-PONTY;2011:85-86).

Para Merleau-Ponty ver um objeto significa habitá-lo (2011:105), percebendo-o sob diferentes ângulos. Vê-se, aí, a importância da vivência do espaço na percepção do objeto fundando a experiência, tal como se dá nas instalações de artemídia contemporânea em que o corpo é convidado a habitar o espaço projetado para a realização de tal experiência. Dessa forma, não nos situamos apenas no espaço, mas somos-com ele a tal ponto que o filósofo francês chega a afirmar que não haveria espaço se não tivéssemos corpo (Ibidem:148). Aí, o corpo não é mais um objeto do mundo, mas sim o meio de comunicação com ele: "Ser uma consciência, ou, antes, ser uma experiência, é comunicar interiormente com o mundo, com o corpo e com os outros, ser com eles em lugar de estar ao lado deles.” (Ibidem:142).

Vejamos o exemplo da obra Ondas: Um Dia de Nuvens Listradas Vindas do Mar $(2006)^{6}$, de Katia Maciel. Em várias de suas obras, a artista trabalha com o conceito de presença por meio de sensores que captam o movimento do participador, desencadeando a interação. Nessa obra, especificamente, ao adentrar a sala vemos uma projeção sobre a parede ao fundo que mostra um vídeo de ondas quebrando na praia, acompanhadas do som característico da ação, o que intensifica ainda mais a sensação proposta pela imagem. No chão vemos a projeção de uma imagem de areia, estática. Ao adentrar o espaço da videoinstalação, nossa presença altera o vídeo que é projetado no chão. Agora as ondas que quebram na praia, vistas na parede, continuam na projeção do chão e nos atingem, como se passassem por baixo de nossos pés, assim como acontece quando estamos à margem da praia entre o mar e a terra. Também o som que acompanha essa ação é o mesmo de quando a onda toma a areia e logo em seguida retorna ao mar. A projeção continua enquanto ali permanecermos.

\footnotetext{
${ }^{6}$ Disponível em $<$ http://vimeo.com/48024392 > . Acessado em 25/03/2016.
} 
A temporalidade da obra não é linear, ela é determinada pelo participador, pela sua relação de movimento com a instalação e se desenrola na dimensão vertical da contemplação subjetiva - sublime matemático, como proposto por $\mathrm{Kant}^{7}$, diante da sensação de infinito trazida pela imagem do oceano, por sua vez também matemático, visto que expresso por imagens binárias digitais. Somos tomados pela imagem luminosa, ela nos atravessa de cima a baixo, espalhando-se sob nossos pés. Estamos imersos na obra e vivenciamos uma experiência transdimensional durante o tempo da experiência participativo-contemplativa, pois nos transportamos para a praia sem sair do prédio do museu. As imagens, o som, a temporalidade, tudo se relaciona às experiências semelhantes já vividas e, retomando o pensamento de Merleau-Ponty, não apenas as recordamos novamente diante do estímulo externo, mas as revivemos em uma nova situação espaço-temporal.

A participação nessas obras, que muitas vezes requer um diálogo entre o estímulo visível e o invisível, pode, segundo Edmond Couchot, ser concebida como real (1998:87), desenvolvendo uma nova matriz perceptual tanto no sentido que envolve seu aspecto digital quanto no sentido psicológico, gerando uma corporeidade que se situa entre a carne e o cálculo (Ibidem:152). Para Suzete Venturelli, estamos diante de um novo paradigma que irá produzir uma subjetividade maquínica. Concordamos com a autora, porém vislumbramos o mesmo processo em sentido inverso: no lugar de conceber uma subjetividade maquínica, acreditamos, assim como propõe Frank Popper, numa humanização da tecnologia por meio da interatividade e da imersão multissensorial tornadas possíveis pela imaginação artística (2001:355). As imagens resultantes dessa interação possibilitam uma percepção que vai além do olhar, que envolve todo o corpo e penetra pelos outros sentidos, tais como audição e tato: "Para o autor [Philippe Quéau], as imagens que surgiram do novo paradigma estético de que nos fala Félix Guattari nunca são somente imagens e se diferenciam destas por possuírem espaço ao redor do que é visualizado e de quem interage.”(VENTURELLI;2011:165).

Os espaços híbridos entre real e imaginário, se embasam fortemente nessa experiência corporal e, diante disso, tornam mais evidente a apropriação do espaço pelo sujeito, que não

\footnotetext{
${ }^{7}$ Em seu livro Crítica da Faculdade do Juízo, Kant afirma que experiência do sublime se encontra entre o horror e o prazer e estaria ligada à percepção da falta de limites, ou ao "absolutamente grande" (2008:93). O sublime, segundo o filósofo, não deve ser procurado nas coisas da natureza, mas em nossa disposição de espírito e ideias (Ibidem:96). No caso de um juízo estético de um objeto sem forma, em que recorreríamos ao sublime, a avaliação da quantidade pode constituir o início do processo (Ibidem: 92-93). No entanto, como na avaliação numérica das grandezas não existe um número máximo (visto que os números vão até o infinito), enquanto na avaliação estética esse máximo é imposto pela subjetividade, podemos até começar o julgamento pelo aspecto quantitativo, mas acabamos sendo levados ao estético, chegando ao sublime-matemático (Ibidem:97).
} 
apenas passa por ele, mas vivencia-o; habita-o. Essa dinâmica pode ser melhor compreendida pelos estados de devaneio. Bachelard afirma que o devaneio é uma fuga para fora do real, mas nem sempre em direção a um mundo irreal (2006:5). Nesse sentido, falamos de uma distensão da consciência, que permite criar e habitar uma topologia imaginária percebida mas, muitas vezes, não visível.

O devaneio se liga mais à experiência que o sonho, pois o devaneio desencadeia processos de recordação no sentido defendido por Merleau-Ponty, que implica reviver tal recordação diante de uma nova situação espaço-temporal. Apenas resgatar uma lembrança da memória, sem vivenciá-la, é o tipo de situação ligada ao sonho, como propõe Bachelard: “A memória sonha, o devaneio, lembra.” (2006:20). No devaneio ainda subsiste uma clareza de consciência necessária à percepção e, consequentemente, à experiência. A consciência que imagina mantém a imagem fruto de sua imaginação num estágio de imediaticidade que acaba por constituir o próprio ser. Não é uma imagem passiva, ela nos desperta de nosso torpor ao criar um mundo próprio. Torna-se possível a elaboração de um mundo estratificado em diversos níveis ontológicos, típico das possibilidades virtualizantes que a tecnologia nos permite hoje por meio das imagens técnicas - para nos referirmos ao termo tão amplamente empregado por Flusser ${ }^{8}$.

Enquanto o sentido das imagens tradicionais seria o de possibilitar uma orientação no mundo, o sentido das imagens técnicas seria o de gerar sentido (FLUSSER; 2008:50). Os aparelhos que geram imagens não são mais refletores, mas projetores e, dessa maneira, podemos criar novas realidades pela manipulação das imagens: "As imagens técnicas tornam imaginável a abstração mais abstrata e o inconcebível em concretamente vivenciável (Ibidem:127). Como, então, distinguir entre essa realidade imaginada e a realidade concreta?

Acreditamos que no universo das imagens técnicas não faz sentido fazer essa distinção, já que imergimos nesse mundo misto, por vezes impalpável, por vezes tangível, mas igualmente, e cada vez mais, naturalmente percebido e vivenciado - um mundo tomado pelo devaneio. Nesse cenário, Pierre Lèvy acredita que um novo tipo de artista aparece. Não mais aquele que apenas conta uma história, mas “um arquiteto do espaço dos acontecimentos,

\footnotetext{
${ }^{8}$ Segundo Flusser, as imagens técnicas constituem virtualidades concretizadas e tornadas visíveis (2008:22). O autor afirma ainda que esse tipo de imagem, a técnica, não ocuparia o mesmo nível ontológico das imagens tradicionais (2008:13).
} 
um engenheiro de mundos para bilhões de histórias por vir. Ele esculpe o virtual." (1996:148).

As obras pensadas para esse fim trabalham sobre a premissa da interação, não esperam que seu sentido se complete, pois não há um sentido específico a ser encontrado. Elas são abertas e podem se configurar de várias maneiras possíveis de acordo com as escolhas do participador. São, geralmente, pensadas sob o formato de instalação, abertas, constituídas de objetos manipuláveis, nas quais se faz o convite ao percurso, tal como se configuram algumas obras sobre as quais já discorremos aqui. Quando tratamos do diálogo entre imagens mentais e visíveis, a partir de uma postura do artista que não impõe uma narrativa, mas se comporta como um arquiteto de espaços para experiências híbridas, não podemos deixar de falar sobre Wave UFO (1999-2002) ${ }^{9}$, de Mariko Mori ${ }^{10}$.

A artista japonesa constrói uma escultura de fibra de carbono em grandes dimensões, chegando a pesar 6 toneladas, no formato de uma gota d'água, disposta como se fosse uma nave espacial. Para adentrar a máquina, subimos por degraus que nos levam ao seu interior, onde 3 cadeiras confortáveis nos convidam a sentar e onde nos ligamos, por meio de eletrodos aderidos à cabeça, a um computador capaz de ler ondas cerebrais - nesse momento não há como não se lembrar da imagem do personagem Neo do filme Matrix (1999), que se liga a uma máquina para entrar no mundo virtual enquanto permanece em repouso sobre uma cadeira no mundo original.

A experiência começa e vemos ser projetadas no teto da "nave" uma sequência de imagens abstratas que correspondem à leitura das ondas de nosso cérebro. Aparecem círculos coloridos em movimento, que aumentam e diminuem de tamanho, mudam de cor, numa sequência que nos intriga, visto ser um espelho de nossa própria mente. Na obra de Mariko Mori, a vontade de externar as imagens mentais se torna possível. Mergulhamos não na imagem, mas no fluxo de nós mesmos, conectados ao fluxo imagético-mental dos outros dois participantes. Experimentamos a sensação de flutuação.

A artista dá continuidade a sua proposta trazendo à visualização imagens de produção própria, do que acredita ser um espelho de sua relação com o cosmos, também por meio de imagens abstratas, muito semelhantes àquelas que externam nossas ondas cerebrais.

\footnotetext{
${ }^{9}$ Disponível em < https://www.youtube.com/watch?v=Q8QbcyKwWNo > Acessado em 25/03/2016.

${ }^{10}$ Mariko Mori (1967 - ) é uma artista contemporânea japonesa que trabalha principalmente com vídeo e fotografia e procura explorar os recursos tecnológicos de ponta para promover a interatividade do participador com a obra.
} 
Vivenciamos aí uma interconexão entre diversos mundos imaginários em que se forma um espaço de interação impalpável. Um labirinto diferente daqueles das instalações de arte contemporânea, ou seja, um labirinto mental no qual cada participante contribui para sua constituição e vivencia uma experiência diferente: visualização de um rizoma de diferentes mundos imaginários, tornada possível pela imagem técnica.

Se relacionarmos a dinâmica de geração de sentido das imagens técnicas ao conceito de $m u n d o^{11}$ em Heidegger, encontraremos alguns pontos em comum. Para o filósofo, o mundo é constituído por uma rede de conexões que geram sentido. Como palco do ser-aí (Dasein), o mundo é compreendido por meio da circunvisão, ou seja, a partir de uma percepção antinômica do mundo, em que não se faz distinção entre o sujeito e o objeto. Para Heidegger, a própria estrutura da existência é antinômica. Na medida em que o homem vê o "todo", ele se vê "essencialmente coinserido nesse todo como algo último, experimenta seu ser-aí como estando ‘envolvido' por esse medium inquebrantável, encontra-se em antinomias.” (2008:23).

O filósofo já alerta para o fato de que a concepção espacial de mundo não está ligada a questões dimensionais, mas a um estar-junto, familiarizado, habitando um mundo experienciável. Bachelard também contribui para tal ponto de vista, ao afirmar que o espaço habitado transcende o espaço geométrico (2008:62). Dessa maneira, se afastarmos a postura de tematização do mundo - que separa o sujeito do objeto —, e optarmos por uma percepção por meio da circunvisão e não da mera observação, esse mundo imagético pode constituir um palco para as experiências do Dasein enquanto ser-no-mundo.

Para Heidegger, o ser-no-mundo "não diz ser dentro do mundo, mas fundamentalmente ser mundo, e isso na experiência de sendo em ser, de existir na dimensão infinitiva de ser.”(2008:27). O ser não está dentro do mundo, o que simplificaria essa relação a uma mera questão espacial. Ser-em pressupõe que o em derive de innan - morar, habitar, deter-se. "O ente ao qual pertence o ser-em, neste sentido, é o ente que sempre eu mesmo sou [...], 'eu sou' diz, por sua vez: eu moro, detenho-me junto... ao mundo, como alguma coisa que, deste ou daquele modo, me é familiar." (HEIDEGGER; 2008:100).

Por isso falamos em devaneio quando adentramos a dimensão dos mundos imaginários criados na relação entre estímulos visíveis e mentais, pois o espaço criado nessa dinâmica não é apenas físico, mas habitado pela experiência. Segundo Bachelard, apenas o devaneio nos

11 Sempre que a palavra 'mundo' vier grifada em itálico é porque nos referimos ao conceito de mundo heideggeriano. 
ajuda a habitar o mundo: "Os mundos imaginados determinam profundas comunhões de devaneios."(2006:23). Para aquele que devaneia, o mundo que habita não se divide na dialética do sujeito e do objeto, ele está muito próximo de seu mundo, ambos estão no mesmo plano do ser, aberto aos possíveis devires: "eu sonho o mundo; logo, o mundo existe tal como eu sonho." (Ibidem:152).

Na videoinstalação Bubbles (2000) ${ }^{12}$, de Wolfgang Muench e Kiyoshi Furukawa ${ }^{13}$, que faz parte do acervo do $Z K M$, podemos vivenciar uma situação de estarmos imersos na imagem ao mesmo tempo em que permanecemos distanciados dela. Aqui, interagimos com as imagens técnicas por meio da projeção da nossa sombra, sozinhos ou acompanhados de outros interatores. O sistema reconhece a movimentação da imagem da sombra e permite a interação dela com as bolhas que aparecem na tela. A cada encontro entre sombra e imagem um som é emitido.

Nosso corpo observa o desenrolar da relação entre os dois tipos de imagem, mas não é um olhar passivo, pois, enquanto observamos, também manipulamos a sombra com nosso movimento. Vemos, aí, o mundo impalpável que se baseia nos algoritmos de comportamento autônomo atribuídos ao deslocamento das bolhas e que se manifesta também no transitar da sombra. Concomitantemente, temos o mundo palpável, do corpo, onde ainda se situam os aparelhos que tornam possível a realização da instalação (projetor, tela, caixas de som, etc.). O espaço da experiência, então, se forma na fronteira entre real e imaginário; palpável e impalpável. No momento da vivência em si, não há distinção, ela só é possível quando habitamos o entre.

Vemos então que, no universo das imagens técnicas, podemos conceber vários aspectos dessa relação do ser-com o mundo que parecem se tornar ainda mais perceptíveis que antes - o que não quer dizer que antes eles não existissem. Nesse contexto, e diante das considerações que levantamos até aqui, cremos poder afirmar que o universo das imagens técnicas é caracterizado pelo mundo significado por essas mesmas imagens, criando o palco para uma possível manifestação do Dasein, que o habita mediante a vivência e compartilhamento de suas experiências. Ou seja, nos referimos a um mundo constituído pelo devaneio, posto que híbrido entre imagens visíveis e mentais e ainda permeado da consciência

\footnotetext{
${ }^{12}$ Disponível em < https://www.youtube.com/watch?v=KMZVX7DcIH8 > Acessado em 25/03/2016.

${ }^{13}$ Wolfgang Muench (1963 - ) é artista e professor da Merz Academy em Stuttgart. Kiyoshi Furukawa (1959 - ) é músico e professor da Tokyo National University of Fine Arts and Music.
} 
da percepção. Segundo Bachelard, para a fenomenologia da imaginação devemos viver diretamente as imagens e considerá-las como acontecimentos súbitos da vida: "quando a imagem é nova, o mundo é novo.”(2008:63).

Arriscamos dizer que, para além de estarmos face-às-imagens como propõe Flusser, no universo das imagens técnicas nós estamos-nas-imagens. Nesse sentido, concebemos um mundo onde é possível habitar uma vida dupla entre real e imaginário, pois não há mais razão de se pensar a distinção entre eles. Quem habita esse mundo é o homem do devaneio, que aí está em toda parte, num dentro que não tem fora: “O mundo já não está diante dele [...] tudo é acolhimento." (BACHELARD;2006:161). Não é à toa que se costuma dizer que o sonhador está imerso no seu devaneio.

\section{REFERÊNCIAS BIBLIOGRÁFICAS}

BACHELARD, Gaston. A poética do espaço. 2 ed. São Paulo: Martins Fontes, 2008. . A poética do devaneio. 2 ed. São Paulo: Martins Fontes, 2006.

COUCHOT, Edmond. La technologie dans l'art. De la photographie à la réalité virtuelle. Nîmes: Éditions Jacqueline Chambon, 1998.

DELEUZE, Gilles. A dobra: Leibniz e o barroco. São Paulo: Papirus, 1991.

DELEUZE, Gilles; GUATTARI, Felix. Mil platôs: capitalismo e esquizofrenia. Vol. 1. São Paulo: Ed. 34, 1995.

FLUSSER, Vilém. O universo das imagens técnicas: elogio da superficialidade. São Paulo: Annablume, 2008.

GOLDBERG, Itzhak. Installations. Paris: CNRS Éditions: 2014.

HEIDEGGER, Martin. Marcas do Caminho; tradução de Enio Paulo Giachini e Ernildo Stein; revisão da tradução de Marco Antônio Casanova. Petrópolis: Vozes, 2008.

KANT, Immanuel. Crítica da Faculdade do juízo. 2.ed. Rio de Janeiro: Forense Universitária, 2008.

LÈVY, Pierre. O que é o virtual. São Paulo: Ed. 34, 1996.

MACHADO. Arlindo. Arte e mídia. Rio de Janeiro: Jorge Zahar, 2010.

MERLEAU-PONTY. Maurice. Fenomenologia da Percepção.4 ed. São Paulo: Martins 
Fontes, 2011.

SIEREK, Karl. Images oiseaux. Aby Warburg et la théorie des medias. Paris: Klincksieck: 2009.

VENTURELLI, Suzete. Arte: espaço_tempo_imagem. Brasília: Editora Universidade de Brasília, 2011. 